\title{
Horseradish peroxidase-labeled rabbit anti-non-structural protein 1 of dengue virus-2 for the diagnosis of dengue virus infections
}

Evy Suryani Arodes, Beti Ernawati Dewi, Tjahjani Mirawati Sudiro

pISSN: 0853-1773 • elSSN: 2252-8083 https://doi.org/10.13181/mji.v28i2.1951 Med J Indones. 2019;28:103-9

Received: January 04, 2018

Accepted: June 28, 2019

\section{Authors' affiliations:}

Department of Microbiology, Faculty of Medicine, Universitas Indonesia, Jakarta, Indonesia

Corresponding author:

Evy Suryani Arodes

Department of Microbiology, Faculty of Medicine, Universitas Indonesia,

Jalan Pegangsaan Timur 16, Cikini, Pegangsaan, Menteng, Central Jakarta 10320, DKI Jakarta, Indonesia

Tel/Fax: +62-21-3100806

E-mail: evy.ard88@gmail.com

\begin{abstract}
BACKGROUND Early diagnosis of dengue virus (DENV) infection is essential for patient management and disease control. Detection of the antigen non-structural protein 1 (NS1) has been proven to provide early diagnosis of DENV infection. Thus, commercial NS1 antigen detection assays have been increasingly used and are becoming the tool of choice among clinicians to confirm DENV infection in Indonesia.
\end{abstract}

METHODS To obtain anti-NS1 DENV antibody, NS1 protein $(90 \mu \mathrm{g} / \mathrm{ml})$ from the collection of the Department of Microbiology, Faculty of Medicine, Universitas Indonesia was injected into a rabbit. The anti-NS1 antibody from the rabbit was then labeled with horseradish peroxidase (HRP) using the periodate oxidation method. Sera were tested by enzyme-linked immunosorbent assay (ELISA) to detect NS1 from DENV-infected patients.

RESULTS Serially diluted antibody labeled with HRP tested using the direct ELISA method showed the highest absorbance value at a 1:100 dilution (Mean [SD] $=1.35$ [0.35]); even at a dilution as high as 1:3,200 (0.22 [0.15]), antibody labeled with HRP was able to detect the NS1 protein, although the absorbance value did not differ greatly from that of the negative control (0.13 [0.01]).

CONCLUSIONS In an attempt to develop an NS1-based diagnostic test, polyclonal antiNS1 DENV antibody was successfully produced as a diagnostic assay to determine the presence of DENV NS1 antigen in patients' sera.

KEYWORDS dengue virus, horseradish peroxidase, NS-1 antigen, polyclonal antibody
Dengue virus (DENV) infection is an important arthropod-born viral infection threatening 2.5 billion people who live in endemic areas worldwide. DENV belongs to the Flaviviridae family and is transmitted to humans by infective female mosquitos of the genus Aedes, especially Aedes aegypti or Aedes albopictus. ${ }^{1,2}$ There are four related but antigenically distinct serotypes of DENV 1-4. DENV causes two types of infection: primary and secondary. Primary infection results in an acute febrile illness known as dengue fever (DF), which is cleared in approximately 7 days by a complex immune response. Secondary infection is more severe and results in dengue hemorrhagic fever (DHF) or dengue shock syndrome.3,4

Rapid and accurate diagnosis of DENV infection is critical for prompt initiation of appropriate clinical care and has been associated with a significant (50to 100 -fold) decrease in mortality from the disease. ${ }^{5}$ Detection of dengue-specific IgM/IgG class antibodies remains the most commonly utilized diagnostic method. However, serologic evaluation has several limitations, including prolonged time to seroconversion (3-7 days), IgM seropersistence following disease resolution, and cross-reactivity with other flaviviruses. ${ }^{6}$ 
Recently, detection of DENV non-structural protein 1 (NS1) has emerged as a potential alternative to both serologic and molecular-based techniques for the diagnosis of active dengue infection. ${ }^{7} \mathrm{NS} 1$ is a non-structural glycoprotein essential for replicability and is detectable within 24 hours and up to 9 days after fever onset. Kinetically, NS1 antigenemia overlaps with the DENV viremia phase and is present prior to IgM seroconversion, positioning the NS1 antigen as a ideal biomarker for identification of acute dengue infection. ${ }^{6,8}$ The NS1 antigen appears in higher concentrations in the sera of DHF patients as compared with those suffering from DF, which indicates its association with disease severity. On account of its high concentration in serum, it could be used for the early diagnosis of DF or DHF with an immune-chromatographic device or enzyme-linked immunosorbent assay (ELISA). 9,10

Indonesia is facing outbreaks of DENV, where the diagnosis and management of DENV infection is the main issue due to the complicated, time consuming, and expensive procedures needed to diagnose infection at an early stage. Commercial NS1 antigen detection assays have been used increasingly often and are becoming the tool of choice among clinicians to confirm DENV infection in Indonesia. In this study, an immunoassay using horseradish peroxidase (HRP)labeled anti-NS1 polyclonal antibody was developed to detect the NS1 antigen in serum, which could ensure rapid, cost-effective, and early diagnosis of DENV infection.

\section{METHODS}

\section{Patients' sera}

A total of 40 clinical samples from the CommunityBased Dengue Study Group Faculty of Medicine, Universitas Indonesia (FMUI), Cipto Mangunkusumo Hospital (Approval number 471/UN2.F1/ETIK/2015) were collected during dengue surveillance in 2010 from a health center in Jakarta. Febrile patients with suspicion of dengue and clinical features suggestive of acute febrile illness, rashes, bleeding tendencies, leucopenia, or thrombocytopenia were evaluated according to the World Health Organization criteria for probable dengue infection and ${ }^{11}$ a previous study ${ }^{12}$ and confirmed to have DENV infection by NS1 (KOREA, NS1 Ag Combo Dengue Duo Kit, Standard Diagnostic Inc), reverse transcription polymerase chain reaction (RT-
$P(R),{ }^{13}$ and the hemagglutination inhibition test. Sera from patients with other viral and bacterial infections were obtained from the collection of the Department of Microbiology, FMUI, Cipto Mangunkusumo Hospital.

\section{Purification of DENV-2 NS1 protein}

DENV-2 NS1 protein belonging to the Department of Microbiology was purified using Sephadex ${ }^{\circledR}$ G-100 (Pharmacia fine chemicals). The NS1 protein was applied to the column, and each fraction was collected in a tube to a total volume of approximately $250 \mu \mathrm{l}$. Fractionation results were tested by $8 \%$ sodium dodecyl sulfate-polyacrylamide gel electrophoresis (SDS-PAGE) and stored at $-30^{\circ} \mathrm{C}$ until use.

\section{Production of anti-NS1 antibody}

Immunogenicity analysis was carried out in a rabbit and conducted in compliance with the ethical standards for animal experimentation of the Health Research Ethics Committee of the FMUI (Approval number 149/UN2.F1/ETIK/2015). The rabbit was immunized by a method described previously, with minor modifications. ${ }^{14}$ Briefly, one male New Zealand White rabbit aged 4 months was immunized with four subcutaneous injections of $90 \mu \mathrm{g}$ of purified DENV type 2 NS1 protein suspended in $100 \mu$ l of Freund's complete adjuvant (FCA, Sigma Aldrich, Missouri) at 1-week intervals. A week after the first immunization, samples of rabbit serum were drawn from the auricular vein. Then, the rabbit was boosted with a suspension of 90 $\mu \mathrm{g}$ in $100 \mu \mathrm{l}$ of Freund's Incomplete Adjuvant (Sigma Aldrich, Missouri) after 3 and 4 weeks. One week after the booster, blood was sampled and tested for anti-NS1 antibody by ELISA to detect the NS1 antigen.

\section{Detection of anti-NS1 antibody in rabbit serum by indirect ELISA}

Indirect ELISA was carried out according to the method described by Igarashi in the Technical manual for the study of arboviruses with special emphasis on Japanese encephalitis and dengue viruses. ${ }^{14}$ Each well was coated with $100 \mu$ l of New Guinea C (NGC) DENV-2 viral culture supernatant $\left(2.1 \times 10^{5} \mathrm{FFU}\right)$ in 1:25 coating buffer $\left(\mathrm{Na}_{2} \mathrm{CO}_{3}, \mathrm{NaHCO}_{3}, \mathrm{pH}\right.$ 9.6) (Disposable Products Pty. Ltd, South Australia), and the plate was incubated overnight at $4^{\circ} \mathrm{C}$. After incubation, the wells were rinsed three times with washing buffer (phosphate buffered saline [PBS] with $0.1 \%$ Tween 20). After washing, non-specific sites were blocked by addition 
of $300 \mu \mathrm{l}$ blocking buffer ( $5 \%$ skim milk [Tropicana Slim, PT. Nutrifood Indonesia, Jakarta] in PBS, pH 7.3) into each well, and the plate was incubated for $30 \mathrm{~min}$ at $37^{\circ} \mathrm{C}$. After incubation, the plate was washed three times with rinse buffer. After washing, $100 \mu$ of 1:50 diluted rabbit serum in $1 \%$ skim milk was added to each well, and the plate was incubated for 1 hour at $37^{\circ} \mathrm{C}$. Excess rabbit serum (primary antibody) was removed by washing the well three times with rinse buffer. After washing, $50 \mu$ l of goat anti-rabbit IgG-HRP (Sigma Aldrich, Missouri) diluted 1:5,000 in 1\% skim milk was added to each well, and the plate was incubated for 1 hour at $37^{\circ} \mathrm{C}$. The excess antibody-enzyme conjugate was removed by washing the well three times with rinse buffer. For detection, $100 \mu$ l of the chromogenic substrate $\mathrm{H}_{2} \mathrm{O}_{2}+\mathrm{TMB}\left(3,3^{\prime}, 5,5^{\prime}\right.$ - tetramethylbenzidine) (Kirkegaard \& Perry Laboratories, Maryland) 1:1 was added to each well, and the plate was incubated for $10 \mathrm{~min}$ at room temperature in the dark until the color developed. The reaction was stopped by addition of $100 \mu$ l of $3 \mathrm{~N}$ sulfuric acid $\left(\mathrm{H}_{2} \mathrm{SO}_{4}\right)$. The absorbance of the colored solution was read at $450 \mathrm{~nm}$ in an automatic microplate ELISA reader (Bio-Rad Model 550, California).

\section{Conjugation of anti-NS1 antibody with HRP}

Before labeling with HRP, the anti-NS1 antibody was purified with Sephadex ${ }^{\circledR} \mathrm{G}-100$ (Pharmacia fine chemicals). The anti-NS1 antibody was conjugated to HRP as described by Ramesh Kumar et al. ${ }^{15}$ First, the HRP was activated by dissolving $2 \mathrm{mg}$ of HRP (Sigma Aldrich, Missouri) in $0.5 \mathrm{ml}$ of distilled water, and 0.2 $\mathrm{ml}$ sodium periodate ( $\mathrm{NalO} 4) 0.1 \mathrm{M}$ was added. The solution was gently inverted for 2 hours at room temperature until the color changed from orange to green. Immediately after incubation, activated HRP was added to $1 \mathrm{ml}$ of antibody solution and incubated for $20 \mathrm{~min}$ at room temperature. After that, $0.2 \mathrm{M}$ $\mathrm{Na}_{2} \mathrm{CO}_{3}$ was added, and the mixture was stirred for 2 hours at room temperature. After 2 hours, $100 \mu \mathrm{l}$ of reductant solution $\left(\mathrm{NaBH}_{4}\right)$ was added, and the solution was mixed for $10 \mathrm{~min}$ at room temperature. Then, the solution was dialyzed in PBS at $4^{\circ} \mathrm{C}$ overnight. The dialysis result was tested by ELISA and stored at $-30^{\circ} \mathrm{C}$ until use.

\section{Binding of HRP-conjugated anti-NS1 antibody to the NS1 antigen}

Binding of anti-NS1 HRP complexes to the NS1 antigen was tested by direct ELISA. First, each well was coated with $100 \mu \mathrm{l}$ of NGC DENV-2 viral culture supernatant in coating buffer (Disposable Products Pty. Ltd, South Australia). The anti-NS1-HRP conjugate was diluted 1:100; 1:200; 1:400; 1:800; 1:1,600; 1:3,200; 1:6,400; and $1: 12,800$ and $100 \mu$ ladded to each reaction. After incubation for 1 hour at $37^{\circ} \mathrm{C}$, the wells were washed, and the substrate was added. The absorbance of the resulting colored solution was read at $450 \mathrm{~nm}$ in an automatic microplate ELISA reader (Bio-Rad Model 550, California).

\section{Detection of the NS1 antigen in patients' sera}

Antibody sandwich ELISA was performed using in-house HRP-labeled rabbit antibody to determine the presence of the NS1 DENV antigen in patients' sera. Briefly, each well was coated with $100 \mu$ of unlabeled serum from an immunized rabbit in coating buffer (Disposable Products Pty. Ltd, South Australia), and the plate was incubated overnight at $4^{\circ} \mathrm{C}$. One hundred microliters of patients' sera was added to each well at a dilution of 1:100 and incubated for 1 hour at $37^{\circ} \mathrm{C}$. After washing, $50 \mu$ of 1:100 diluted HRPlabeled anti-NS1 antibody was added to each well, and the plate was incubated for 1 hour at $37^{\circ} \mathrm{C}$. Excess antibody-enzyme conjugate was removed by washing the well three times with washing buffer. Then, $100 \mu \mathrm{l}$ of the chromogenic substrate (tetramethyl benzidine/ hydrogen peroxide) was added to each well, and the plate was incubated for $10 \mathrm{~min}$ at room temperature until the color developed. The reaction was stopped with $1 \mathrm{~N}$ sulfuric acid, and the absorbance of the colored solution was read at $450 \mathrm{~nm}$ in an automatic microplate ELISA reader (Bio-Rad Model 550, California).

\section{RESULTS}

\section{Purification of DENV-2 NS1 protein}

In this study, DENV-2 NS1 protein with a molecular weight of $46 \mathrm{kDa}$ was used from the collection of the Department of Microbiology. The presence of purified protein was confirmed using SDS-PAGE 8\%. SDS-PAGE showed a single band corresponding to a molecular weight of $\sim 46 \mathrm{kDa}$ in fractions 12-15, which was identified as the NS1 protein. Fractions 10 and 11 also contained NS1 protein, but the band was very thin. In fractions 8 and 9 there were protein impurities despite the 


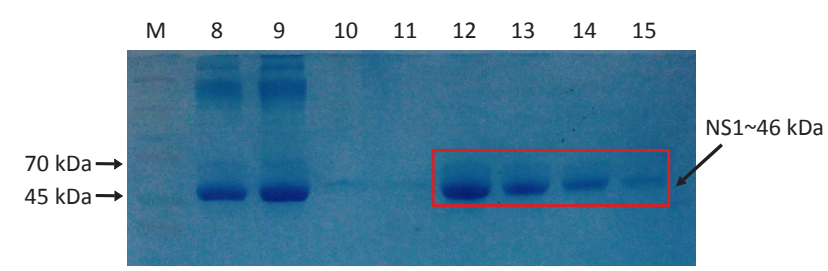

Figure 1. SDS-PAGE results for the NS1 protein with a single band of $\sim 46 \mathrm{kDa}$ in fraction $12-15$. M=protein marker; 8-15=protein fractions after purification with Sephadex G-100

presence of protein bands corresponding to NS1 (Figure 1). Therefore, the NS1 protein used to immunize the rabbit was from fractions 12, 13, 14, and 15. The presence of NS1 protein was also confirmed using the Dengue NS1 Ag + Antibody Combo Dengue Duo Kit, Standard Diagnostic Inc (immunochromatography strip) and showed a positive result (data not shown).

\section{Production of the anti-NS1 antibody}

The NS1 protein was injected into the rabbit at a concentration of $90 \mu \mathrm{g} / \mathrm{ml}$ as a single initial injection and three booster injections. After immunization, blood sampling was performed four times. The first blood collection was carried out 1 week after immunization (Code $\mathrm{w}-1$ ). The next blood samples were collected in the sixth, seventh, and ninth weeks after the last booster injection (Code w-6, w-7, and w-9, respectively). All of the sera were tested by indirect ELISA using virus supernatant as the antigen. This assay was performed to determine the induction of anti-NS1 antibodies in rabbit serum. The results of ELISA showed that the visible absorbance value of the preimmunization serum negative control was low $(0.21$ [0.11]). The result was obtained with the negative control (0.20 [0.12]).
The absorbance value began to increase in $\mathrm{w}-1$ ( 1.27 [0.42]) and continued to increase to 3.06 (0.17) in w-9. Therefore, only $w-9$, with the highest OD value, was further purified and labeled with HRP. Sephadex G-100 was used to obtain pure IgG antibodies (Figure 2).

\section{Conjugation of anti-NS1 antibody with HRP}

Testing of the serially diluted HRP-labeled antibody using the direct ELISA method showed the highest absorbance value in the 1:100 dilution (1.35 [0.35]); even when diluted to 1:3200 (0.22 [0.15]), the HRP-labeled antibody could detect the NS1 protein, although the value did not differ greatly from that of the negative control (0.13 [0.01]) (Figure 3). The absorbance of the labeled antibody was half that of the unlabeled rabbit antibody, presumably due to the dilution effect. This may have been largely due to attachment of HRP to the fragment of antigen binding, which disrupted the binding of HRP-labeled antibody to the NS1 antigen.

\section{Detection of NS1 antigen in patient's sera}

The w-9 antibody labeled with HRP was also used to detect NS1 antigen in the sera of patients infected with DENV, DENV-negative patients, and healthy people, by using sandwich ELISA. The test results indicated that the HRP-labeled antibody was able to detect the NS1 antigen, including DENV-1 (10 samples), DENV-2 (10 samples), DENV-3 (10 samples), and DENV-4 (10 samples), in all patients' sera. To determine whether w-9 antibody labeled with HRP cross-reacted with other antigens, patients' sera infected with cytomegalovirus and Epstein-Barr virus was used and found no crossreaction with antigens of other viruses.
Figure 2. Comparison of the rabbit anti-NS1 antibody fraction determined by indirect ELISA. After immunization, blood sampling was performed four times. The first blood collection was carried out 1 week after immunization. Subsequent blood samples were collected in the sixth, seventh, and ninth weeks after booster injection. At week 1, the mean (SD) of absorbance value begin to increase and continued to increase to at week 9.

Negative control=pre-immune rabbit serum

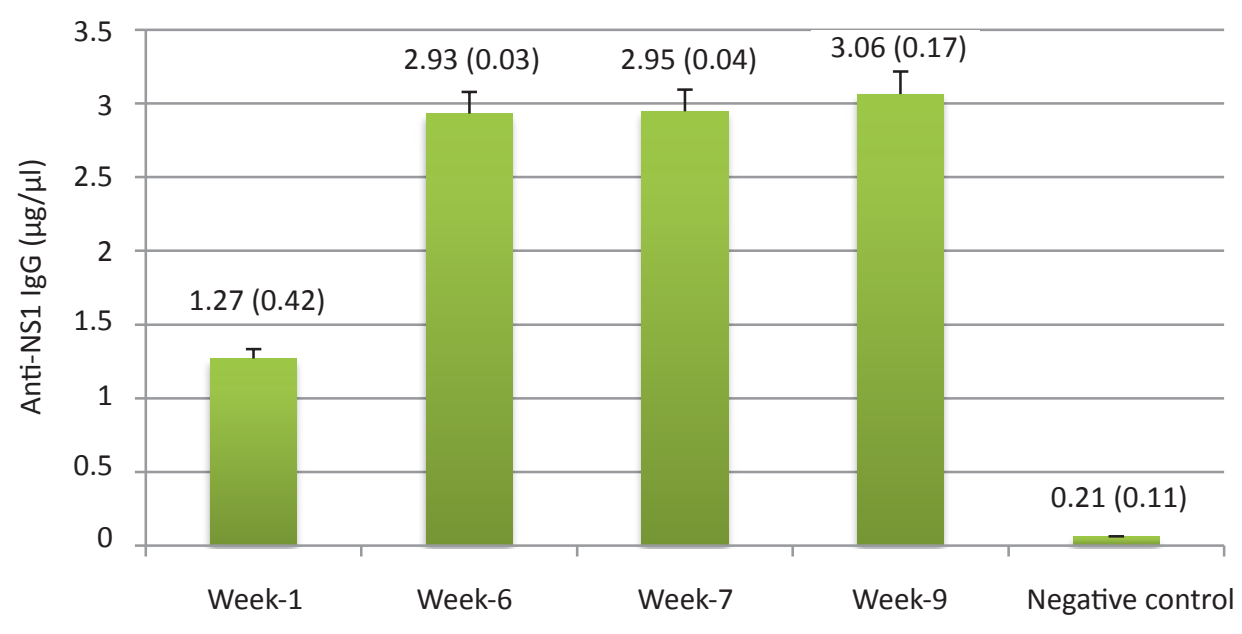

Fraction of rabbit serum

mji.ui.ac.id 


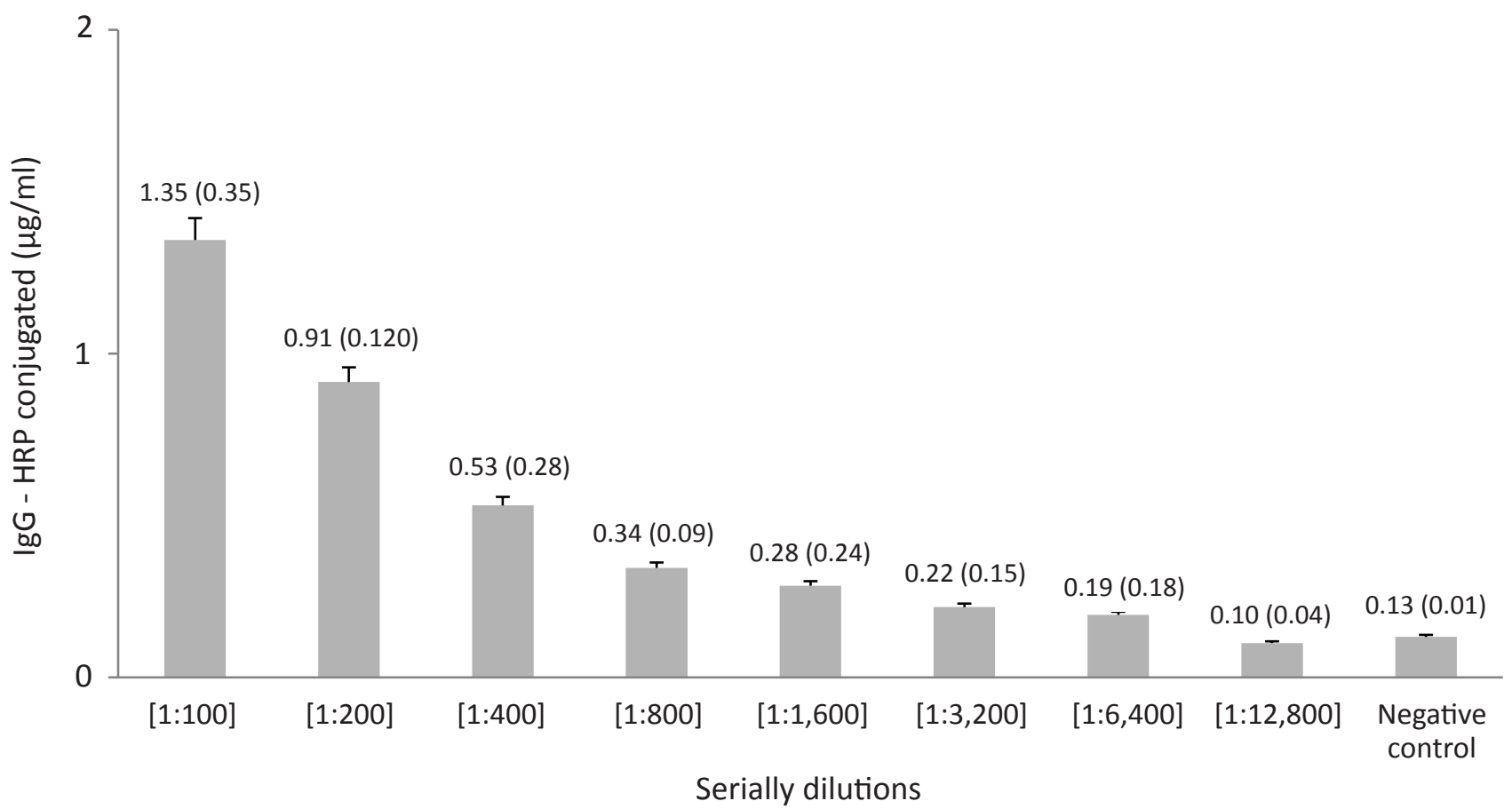

Figure 3. Direct ELISA to confirm the interaction of the NS1 antigen and HRP-conjugated anti-NS1. The mean (SD) of results were obtained using an HRP-conjugate $(2 \mu \mathrm{g} / \mathrm{ml})$ prepared through periodate conjugation methods as the secondary antibody

\section{DISCUSSION}

Rapid and early diagnosis of DENV infection can lead to early therapeutic intervention and have a significant effect on patient recovery. ${ }^{16}$ Detection of the dengue NS1 antigen is suggested as a helpful tool for the early diagnosis of dengue infection after the onset of fever in primary and secondary infection. The NS1 antigen has been found circulating from the first day after the onset of fever up to day 9, once the clinical phase of the disease is over. ${ }^{17}$ The NS1 protein is a highly conserved glycoprotein and is believed to be responsible for the pathogenicity of DENV. Therefore, it can be a good candidate antigen for the diagnosis of dengue infection. ${ }^{18}$ NS1 is an ideal diagnostic marker due to its presence at high levels in the blood of infected individuals very early in infection, typically at or before symptom onset. ${ }^{19}$

The NS1 protein could be detected even when the sample tested negative for viral RNA in RT-PCR or in the presence of immunoglobulin $M$ antibodies. The levels of circulating NS1 in acute-phase serum samples are within the range of $10 \mu \mathrm{g} / \mathrm{ml}$ to $50 \mu \mathrm{g} / \mathrm{ml}$ and do not differ significantly between primary and secondary infection. ${ }^{14}$ The commercial development and application of NS1 detection as a diagnostic tool has revolutionized dengue diagnosis and now provides a simple and relatively low-cost assay with high sensitivity and specificity. More recent studies have shown that NS1 detection may also be applicable to the diagnosis of other flavivirus infections. ${ }^{20}$ Recently, commercial diagnostic NS1 kits have become available in Indonesia and show variable specificities and sensitivities. The sensitivity of some NS1 antigen assays ranged from $29-88 \%$, and the specificity ranged from $89-100 \% .{ }^{1,7}$ The reasoning behind the disparate sensitivities between kits, serotypes, and geographical sites requires further study. The difference may reflect different levels of avidity of the test monoclonal antibody for the relevant epitope(s) in NS1 from different serotypes and potentially different lineages from the same serotype, as well as differences in the viral burden between serotypes. ${ }^{1}$ The other limitation of the NS1 diagnostic kit is its inability to distinguish one dengue serotype from another. Qiu et $\mathrm{al}^{21}$ developed an NS1 antigen assay using a monoclonal antibody that successfully differentiated DENV-2 from other serotypes with $83.3 \%$ sensitivity and $100 \%$ specificity. Overall, the results of these studies suggest that the currently available NS1 antigen detection kits require further improvement, mainly with respect to their sensitivity.

In the case of polyclonal antibodies, animals are given injections of antigen or antigen/adjuvant 
mixtures to induce an effective antibody response, and it is usually necessary to collect blood to monitor the antibody response during the experiment and to obtain antibodies. When the antigen to which antibodies are to be raised is poorly immunogenic, the immune system requires a stimulus to induce an effective immune response. Adjuvants can be used for this purpose and can induce cellular or humoral responses. FCA is used frequently for the production of polyclonal antibodies because high antibody titers are induced to almost all types of antigens. ${ }^{22}$

Conjugation of enzymes to antibodies involves the formation of a stable, covalent linkage between an enzyme, such as HRP, and an antibody. This enzyme is inexpensive and can be attached to the immune reagent by a variety of methods. Moreover, many chromogenic substrates for it are also available. An ideal conjugation reaction would be the labeling of each IgG with one molecule of HRP without loss of immunologic or enzymatic activities. Some aspects of this ideal reaction may be compromised, but others cannot be without loss of sensitivity of the method. For example, during the reaction, HRP should not lose its enzymatic activity, because IgG labeled with enzymatically inactive HRP will act as unlabeled IgC and compete for the antigenic sites. The conjugation of HRP to an antibody depends on the generation of aldehyde groups by periodate oxidation of the carbohydrate moieties on HRP. Combination of these active aldehydes with amino groups on the antibody forms a Schiff base upon reduction by sodium borohydride, thus stabilizing the conjugate. ${ }^{15,23}$

In this study, the w-9 antibody labeled with HRP was also used to detect NS1 antigen in the serum of patients infected DENV, DENV-negative patients, and healthy people, by using sandwich ELISA. The test results indicate that the $\mathrm{HRP}$-labeled antibody was able to detect the NS1 antigen, including DENV-1, DENV2, DENV-3, and DENV-4, in all patients' sera. This was due to similarities in the DENV-2 NS1 epitope among serotypes. Based on the results of sequencing the NS1 epitope of DENV-2, B-cell epitopes at amino acids 25-33, 112-116, and 299-303, have an amino acid that is highly conserved among all four serotypes of DENV. ${ }^{24,25,26}$ Therefore, the antibody labeled with HRP could be used to develop a diagnostic assay to determine the presence of the DENV NS1 antigen in patients' sera, because early diagnosis of DENV infection is beneficial to patient management and disease control.
A limitation of this study was the unavailability of control sera from patients infected with Flaviviridae or Togaviridae. Therefore, sera from patients infected with other viruses were used. Moreover, further research is needed regarding the optimization of the labeling process to produce an HRP-labeled rabbit anti-NS1 DENV that can detect the NS1 protein at even lowest dilutions.

\section{Conclusions}

In summary, at presentase the data shows that kit candidate can potentially used for diagnosis of dengue infection. Accuracy and rapidity should be explored in larger study.

\section{Conflict of Interest}

The authors declare that there is no conflict of interest regarding the publication of this paper.

\section{Acknowledgment \\ None.}

\section{Funding Sources}

This study was supported by grant of Publikasi Terindeks Internasional untuk Tugas Akhir Mahasiswa UI (PITTA) 2018. NO: 0588/SK/R/UI/2018.

\section{REFERENCES}

1. Guzman MG, Halstead SB, Artsob H, Buchy P, Farrar J, Gubler DJ, et al. Dengue: a continuing global threat. Nat Rev Microbiol. 2010;8(12 Suppl):S7-16.

2. Halstead SB. Dengue. Lancet. 2007;370(9599):1644-55.

3. Idrees S, Ashfaq U. A brief review on dengue molecular virology, diagnosis, treatment and prevalence in Pakistan. Genet Vaccines Ther. 2012;10(1):6.

4. Fatima Z, Idrees M, Bajwa MA, Tahir Z, Ullah O, Zia MQ, et al. Serotype and genotype analysis of dengue virus by sequencing followed by phylogenetic analysis using samples from three mini outbreaks-2007-2009 in Pakistan. BMC Microbiol. 2011;11:200.

5. World Health Organization (WHO). Global Strategy for Dengue Prevention and Control. Geneva, Switzerland; WHO: 2012.

6. Anderson NW, Jespersen DJ, Rollins L, Seaton B, Prince HE, Theel ES. Detection of the dengue virus NS1 antigen using enzyme immunoasaay. Diagn Microbiol Infect Dis. 2014;79(2):194-7.

7. Wang SM, Sekaran SD. Evaluation of a commercial SD dengue virus NS1 antigen capture enzyme-linked immunosorbent assay kit for early diagnosis of dengue virus infection. J Clin Microbiol. 2010;48(8):2793-7.

8. Kassim FM, Izati MN, TgRogayah TA, Apandi YM, Saat Z. Use of dengue NS1 antigen for early diagnosis of dengue virus infection. Southeast Asian J Trop Med Public Health. 2011;42(3):562-9.

9. Hussain A, Rehman SU, Aslam S, Javed N, Abbas Z. Nano-gold particles mediated detection of NS1: an early diagnostic marker of dengue virus infection. J Anim Plant Sci. 2014;24(4):1110-5.

10. Pelling RW, Artsob H, Pelegrino JL, Buchy P, Cardosa MJ, Devi $S$, et al. Evaluation of diagnostic tests: dengue. Nature Rev Microbiol. 2010;8(12 Suppl):S30-8.

11. World Health Organization (WHO). Dengue haemorrhagic fever, treatment, prevention and control. 2nd Ed. Geneva, WHO. 2009. 
12. Dewi BE, Naiggolan L, Putri DH, Rachmayanti N, Albar S, Indriastuti NT, et al. Characterization of dengue virus serotype 4 infection in Jakarta, Indonesia. Southeast Asian J Trop Med Public Health. 2014;45(1):53-61.

13. Santiago GA, Vergne E, Quiles Y, Cosme J, Vazquez J, Medina JF, et al. Analytical and clinical performance of the $C D C$ real time RT-PCR assay for detection and typing of dengue virus. PLoS Negl Trop Dis. 2013;7(7):e2311.

14. Alcon S, Talarmin A, Debruyne M, Falconar A, Deubel V, Flamand M. Enzyme-linked immunosorbent assay specific to dengue virus type 1 nonstructural protein NS1 reveals circulation of the antigen in the blood during the acute phase of disease in patients experiencing primary or secondary infections. J Clin Microbiol. 2002;40(2):376-81.

15. Ramesh Kumar K, Xiavour S, Latha S, Kumar V, Sukumaran. Anti-human IgG-horseradish peroxidase conjugate preparation and its use in ELISA and Western blotting experiments. J Chromatograph Separat Techniq. 2014;5(1):211.

16. Vaughn DW, Green S, Kalayanarooj S, Innis BL, Nimmannitya S, Suntayakorn $\mathrm{S}$, et al. Dengue viremia titer, antibody response pattern, and virus serotype correlate with disease severity. J Infect Dis. 2000;181(1):2-9.

17. Shu PY, Chen LK, Chang SF, Yueh YY, Chow L, Chien LJ, et al. Potential application of nonstructural protein NS1 serotypespecific immunoglobulin $G$ enzyme-linked immunosorbent assay in the seroepidemiologic study or dengue virus infection: correlation of results with those of the plaque reduction neutralization test. J Clin Microbiol. 2002;40(5):1840-44.

18. Chuang YC, Wang SY, Lin YS, Chen HR, Yeh TM. Re-evaluation of the pathogenic roles of nonstructural protein 1 and antibodies during dengue virus infection. J Biomed Sci. 2013;20:42.

19. Muller DA, Young PR. The flavivirus NS1 protein: molecular and structural biology, immunology, role in pathogenesis and application as a diagnostic biomarker. Antiviral Res. 2013;98(2):192-208.

20. Huang JL, Huang JH, Shyu RH, Teng CW, Lin YL, Kuo MD, et al. High-level expression of recombinant dengue viral NS-1 protein and its potential uses as a diagnostic antigen. J Med Virol. 2001;65(3):553-60.

21. Qiu LW, Di B, Wen K, Wang XS, Liang WH, Wang YD, et al. Development of an antigen capture immunoassay based on monoclonal antibodies specific for dengue virus serotype 2 nonstructural protein 1 for early and rapid identification of dengue virus serotype 2 infections. Clin Vaccine Immunol. 2009;16(1):88-95.

22. Leenaars M, Hendriksen CF. Critical steps in the production of polyclonal and monoclonal antibodies: evaluation and recommendations. ILAR J. 2005;46(3):269-79.

23. Ray S, Das N, Bishayi B. Development of a simple method for a new immunoconjugate utilizing laccase. Research Journal of Immunology. 2012;5(1):1-16.

24. Falconar AK. Antibody responses are generated to immunodominant ELK/KLE-type motifs on the nonstructural-1 glycoprotein during live dengue virus infections in mice and humans: implications for diagnosis, pathogenesis, and vaccine design. Clin Vaccine Immunol. 2007;14(5):493-504.

25. Falconar AK. Monoclonal antibodies that bind to common epitopes on the dengue virus type 2 nonstructural-1 and envelope glycoproteins display weak neutralizing activity and differentiated responses to virulent strains: implications for pathogenesis and vaccines. Clin Vaccine Immunol. 2008;15(3):549-61.

26. Wu HC, Huang YL, Chao TT, Jan JT, Huang JL, Chiang HY, et al. Identification of B-cell epitope of dengue virus type 1 and its application in diagnosis of patients. J Clin Microbiol. 2001;39(3):977-82. 